ÄTHIOPISTISCHE FORSCHUNGEN

BAND 25 


\title{
ÄTHIOPISTISCHE FORSCHUNGEN
}

\author{
HERAUSGEGEBEN VON \\ ERNST HAMMERSCHMIDT
}

BAND 25

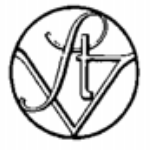

FRANZ STEINER VERLAG WIESBADEN GMBH STUTTGART 1987 


\section{ERNST HAMMERSCHMIDT}

\section{STUDIES \\ IN THE ETHIOPIC \\ ANAPHORAS}

SECOND REVISED EDITION

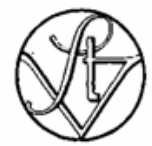

FRANZ STEINER VERLAG WIESBADEN GMBH STUTTGART 1987 
Titelvignette: Adelheid Kordes, Aschaffenburg

Gedruckt mit Unterstützung der

Johanna und F ritz Buch-Gedächtnisstiftung

CIP-Kurz titelaufnahme der Deutschen Bibliothek

Hammerschmidt, Ernst:

Studies in the Ethiopic anaphoras / Ernst Hammerschmidt. - 2., rev. ed. - Stuttgart : SteinerVerlag-Wiesbaden-GmbH, 1987.

(Äthiopistische Forschungen ; Bd. 25)

1. Aufl. im Akad.-Verl., Berlin

ISBN 3-515-04827-8

NE: GT

Vom Akademie-Verlag Berlin genehmigte Lizenzausgabe für den Vertrieb in den nichtsozialistischen Ländern.

() Akademie-Verlag Berlin. Printed in GDR 